\title{
Violencias contra las mujeres: análisis de tres novelas africanas recientes
}

\author{
Violence against women: analysis of three recent African novels
}

\author{
Adriana Franco Silva \\ Universidad Nacional Autónoma de México; \\ Facultad de Ciencias Políticas y Sociales (México) \\ afrasi.16e@gmail.com \\ adriana.franco@politicas.unam.mx
}

\begin{abstract}
Resumen
A partir del establecimiento de la colonización en el continente africano, las historias de las mujeres han sido omitidas o malinterpretadas. El proyecto de modernidad colonialcapitalista-patriarcal se sustenta en la violencia y subordinación de lo que identifica como otro. Por eso, a partir de su implementación en África, las relaciones de poder y los sentidos de mundo del continente fueron modificados. En esa estructura, las violencias contra las mujeres se posicionaron como un elemento central para la reproducción del sistema.

A pesar de eso, diversas mujeres africanas han rescatado sus historias y las de sus ancestras. Asimismo, la literatura se ha convertido en una herramienta para recuperar esas memorias, cuestionar las violencias y delinear la dignidad. Así, las preguntas que guiarán este estudio son ¿de qué manera se representan, en los textos literarios, las opresiones que han vivido las mujeres a partir de la instauración del proyecto de modernidad? ¿cuál es el objetivo de enunciar estas violencias? Estos cuestionamientos serán respondidos a partir del análisis de tres novelas africanas recientes: Volver a casa de Yaa Gyasi, La flor púrpura de Chimamanda Ngozi Adichie y Florescencia de Kopano Matlwa.
\end{abstract}

\section{Palabras Clave}

Modernidad colonial-capitalista-patriarcal; violencia contra las mujeres; historias africanas; literatura africana; decolonialidad.

\begin{abstract}
Since the establishment of colonization on the African continent, women's stories have been omitted or misunderstood. The project of colonial-capitalist-patriarchal modernity resulted in the violence and subordination of what it identifies as the other. For this reason, power relations and world views of the African continent were modified. In this structure, violence against women was positioned as a central element for the reproduction of the system.

Notwithstanding, various African women have recuperated their stories and those of their ancestors. Literature has become a tool to recover those memories, question violence while emphasizing dignity. Thus, the questions that will guide this study are: How are oppressions experienced by women represented, in literary texts, since the establishment of the project of modernity? What is the objective of such an analysis? These questions will be answered
\end{abstract}


from the analysis of three recent African novels: Homegoing by Yaa Gyasi, Purple Hibiscus by Chimamanda Ngozi Adichie and Period Pain by Kopano Matlwa.

\section{Keywords}

Colonial-capitalist-patriarchal modernity; violence against women; resistances; African histories; African literature; decoloniality.

La modernidad colonial-capitalista-patriarcal ${ }^{1}$, que se sustenta en el dualismo cartesiano, ha representado al continente africano y a sus habitantes en una relación de subordinación debido a que sus conocimientos, cuerpos, sentires y pensares han sido imaginados como el polo opuesto de lo que en ese sistema se identifica como moderno. Algunos de los ejes de dominación que han dado sustento a estas jerarquizaciones son: la raza, la clase y el género, los cuales, al ser analizados desde una perspectiva interseccional, permiten rastrear omisiones, malas interpretaciones y violencias ejercidas contra las mujeres del continente africano a partir de la instauración de dicha modernidad.

En África, este sistema fue cimentado durante la esclavitud e impuesto a partir de la colonización europea, instaurando un patriarcado hiperviolento que, en algunos casos, incrementó las desigualdades existentes entre hombres y mujeres, y en otros las erigió. Las mujeres africanas no han sido pasivas frente a esta subordinación. No obstante, sus luchas, prácticas y resistencias no han sido recuperadas por la llamada "Historia universal". Así, a pesar de que las mujeres han sido profundamente violentadas y excluidas por este sistema, ellas siguen resistiendo, recuperando su memoria histórica y organizándose para contrarrestar esas violencias y modificar las relaciones desiguales impuestas.

Sus resistencias, movilizaciones y organizaciones han estado presentes en todos los ámbitos de la vida y también han abarcado diferentes estrategias, las cuales van desde las institucionales hasta las antisistémicas, y de la apropiación de espacios físicos a la de espacios mentales, los cuales son fundamentales para diseñar alternativas reales frente a las relaciones de subordinación, debido a que las funciones imaginativas constituyen a las y los sujetos. En ese sentido, los objetos culturales adquieren significancia justamente a partir de esas cosmogonías (Schwab, 1984, p. 454). De tal suerte, intervenir en las producciones culturales es fundamental para transformar relaciones sociales que se han reificado a lo largo de los años.

\footnotetext{
${ }^{1}$ Este concepto ha sido utilizado por diversos/as autores de la teoría decolonial para referirse a la modernidad capitalista, que se proyectó históricamente por medio de la colonización, generando dicotomías jerarquizadas (blanco/negro, rico/pobre, hombre/mujer, entre otras) a partir de las cuales se violenta a la otredad (Grosfogel, 2018). El patriarcado es una característica esencial de este sistema, por eso, "un acercamiento interseccional no estudiaría al capitalismo y al patriarcado de manera separada" (Tamale, 2020, 68).
} 
La literatura es uno de los espacios que han sido reapropiados por las mujeres. Así, aunque las novelas son objetos culturales, estas tienen una intencionalidad política. Es decir, la recuperación de la memoria a partir de narraciones no sólo es una forma de explicar o representar un proceso histórico, también implica visibilizar opresiones para exigir un cambio y/o plantear alternativas. De tal suerte, en este texto se analizarán las maneras en las que tres autoras africanas comparten las opresiones que viven, o que han vivido sus ancestras, a partir del establecimiento de la modernidad colonial-capitalista-patriarcal.

Se han seleccionado tres novelas para lograr ese objetivo: Volver a casa de Yaa Gyasi (2016), La flor púrpura de Chimamanda Ngozi Adichie (2003) y Florescencia de Kopano Matlwa (2018). La variable principal para la selección de las novelas fue la representación de la violencia contra las mujeres a partir de los enfoques de escritoras africanas jóvenes. En las tres obras se incorpora el tema, pero no desde una perspectiva estática, ya que la enuncian, la critican y dibujan alternativas. Asimismo, los relatos se sitúan en diferentes contextos históricos y espacios temporales, lo que permite analizar la reconfiguración de la violencia con la modernidad como un procesos estructural y global.

Las tres autoras escribieron sus novelas en el siglo XXI, lo cual es relevante para identificar las maneras en que las nuevas generaciones están entendiendo su realidad y proponiendo la transformación social. En dos de las narraciones se recuperan las historias de la instauración de la modernidad colonial-capitalistapatriarcal en el territorio africano (esclavitud y colonización), mientras que la tercera describe el reforzamiento de esta estructura en el continente (neoliberalismo).

Así, este artículo comenzará señalando la vinculación entre el proyecto de la modernidad y las violencias contra las mujeres, para posteriormente analizar cada una de las novelas. Se iniciará con Volver a casa y se enfatizarán las implicaciones del proceso de esclavitud, posteriormente se estudiará La flor púrpura para identificar las violencias en el periodo colonial y postcolonial y, finalmente, Florescencia para hacer el análisis de la etapa neoliberal.

\section{La modernidad colonial-capitalista-patriarcal y la violencia contra las mujeres en África}

Cuando se estudia el papel de las mujeres africanas durante el periodo precolonial, éstas son analizadas, generalmente, a partir de dos paradigmas: 1) las mujeres como heroínas, lideresas y guerreras que, en algunos casos, combatieron la presencia colonial, como lo ejemplifican las guerreras de Dahomey, Njinga Mbandi o Ranavalona I, y 2) las mujeres como víctimas de las "dinámicas bárbaras africanas", que las representan como sujetas oprimidas que fueron liberadas gracias a la presencia colonial europea (Ogbomo y Ogbomo, 1993, 431). Sin embargo, a pesar de que se podría pensar que el primer modelo reivindica el papel de las mujeres en el 


\section{Adriana Franco Silva}

continente, en realidad ambos prototipos responden a la lógica de la modernidad colonial-capitalista-patriarcal.

En el primer caso, se resaltan las relaciones de poder basadas en estructuras jerárquicas y militares, por lo que el poder se piensa como algo que se concentra y se posee, lo cual elimina su carácter relacional y solo se puede entender bajo la lógica del individualismo. En este sentido, considero que para poder comprender las dinámicas africanas precoloniales, es necesario que estas historias analicen al poder como un elemento difuso y comunitario, no solo como algo que poseía o concentraba una mujer.

El segundo paradigma, es más problemático debido a que justifica la colonización como una forma de liberación de las mujeres africanas, lo cual sigue reproduciendo discursos dicotómicos de lo moderno-civilizado-europeo y lo tradicional-bárbaroafricano. Asimismo, al sobrerrepresentar las desigualdades entre hombres y mujeres, se pretende naturalizar y normalizar el patriarcado como estructura social. No obstante, en este trabajo se cuestiona el predominio del patriarcado en todas las formas sociales de organización, porque este sistema se configura a partir de objetivos particulares y se asocia directamente con los intereses de los grandes capitales.

Asimismo, aceptar que el patriarcado es esencial a todas las formas de organización humanas (Segato, 2016) implicaría, de manera indirecta, pensar que es imposible transformar esa estructura, por lo que en este artículo se plantea que, aunque el sistema moderno-colonial-capitalista-patriarcal es actualmente el hegemónico, anteriormente había otras maneras de relacionarse socialmente y éstas no implicaban, necesariamente, la humillación o aniquilamiento de lo que se percibía como diferente, como lo han demostrado los trabajos de Tamale (2020), Nzegwu (1994) y Amadiume (2017).

Así, ambos paradigmas tienen, en términos de Oyèwùmi (2017), un sesgo androcéntrico y colonial. Esto se puede entender debido a que la historia del continente africano fue recuperada, principalmente, por hombres blancos y cristianos, por lo que sólo se rescataron las historias que permitían demostrar el supuesto salvajismo de los pueblos africanos o las que garantizaban la reproducción del sistema. Asimismo, la historia del continente africano fue recuperada por, para y sobre hombres, excluyendo las instituciones, prácticas e historias de las mujeres, lo que a su vez sustentó y reprodujo las violencias cometidas contra ellas (Lefatshe y Mtombeni, 2020, p. 2).

Oyèwùmi menciona que la razón occidental se sustenta en la percepción del mundo a partir de lo visual, por eso, las clasificaciones y jerarquizaciones humanas se han hecho en términos del color de la piel, de los órganos sexuales, entre otros (2017, 39). Para ejemplificar su afirmación, Oyèwùmi señala que antes de la colonización europea sobre el continente africano, las relaciones sociales de las poblaciones yorùbá no estaban delimitadas por una relación sexo-diferenciada a partir de lo visual, y que los conocimientos se producían desde los sentidos de mundo y no sólo de las cosmovisiones. 
Así, la modernidad colonial-capitalista-patriarcal eliminó otras formas de aprehender y explicar al mundo, colocando su punto de enunciación como el único válido. En esta producción de conocimientos, los saberes de los africanos y en particular los de las mujeres fueron marginados. Por ejemplo, para la modernidad, la razón se vincula con lo masculino, mientras que la sensibilidad — que justamente plantea la capacidad de percibir al mundo desde los sentidos - sería subordinada y asociada con lo irracional y lo femenino (Comaroff y Comaroff, 2010, 38).

Sin embargo, la modernidad no sólo negaría o relegaría otros conocimientos y formas de aprender, su instauración también produciría nuevas relaciones de poder que tuvieron el objetivo de reprimir a las poblaciones africanas a partir de la imposición de categorías que antes no existían en el continente como raza, clase y género (Cabanillas, 2020).

En los discursos coloniales, "África fue reducida al cuerpo de una mujer negra rindiéndose al descubrimiento del hombre blanco" (Comaroff y Comaroff, 2010, 38), lo que auguraría la invisibilización de las actividades, instituciones e historias de las mujeres africanas y la violencia hacia sus cuerpos, pensares y sentires. El sistema moderno-colonial-capitalista-patriarcal se basaría en un orden social violento. Así, el contacto con la modernidad ha implicado la institucionalización de la violencia contra las mujeres, que en la Resolución № 48/104 de Naciones Unidas se define como:

todo acto de violencia basado en la pertenencia al sexo femenino que tenga o pueda tener como resultado un daño o sufrimiento físico, sexual o psicológico para la mujer, así como la amenaza de tales actos, la coacción o la privación arbitraria de la libertad, tanto si se produce en la vida pública como en la vida privada.

Sin embargo, la violencia contra las mujeres no sólo se entiende porque son mujeres, sino también por otras dimensiones que las constituyen como personas: la raza, la clase, la sexualidad, entre otras (Crenshaw, 1991, 1242). De tal suerte, las violencias contra las mujeres africanas no sólo deben ser analizadas a partir de una abscisa, sino desde la intersección de las diversas opresiones. Estudiar las violencias contra las mujeres desde la interseccionalidad no implica hacer una suma de opresiones, sino entender cómo éstas se entrecruzan en contextos espacio-temporales particulares (Tamale, 2020, 65).

Para este texto, la violencia se desglosará en tres tipos: la directa, que implica afectaciones físicas contra los cuerpos y que puede llegar a la muerte; la estructural, que es la violencia inherente al sistema y que configura las desigualdades, injusticias sociales y relaciones de poder; y la simbólica o cultural, que supone un maltrato emocional y estigmatizaciones, generalmente a través de los discursos (Fernández de la Reguera, 2017; Cejas, 2000; González, 2017).

A partir de la instauración del proyecto moderno colonial, estas violencias atravesaron los cuerpos, mentes y sentires de las mujeres en el continente africano. En diversas obras literarias estas violencias han sido enunciadas con el objetivo de 
recuperar memorias, pero también para cuestionar las relaciones sociales dominantes y crear imaginarios para la transformación.

\section{Volver a casa y los cimientos del patriarcado hiperviolento en el continente africano}

En la actualidad, mujeres jóvenes africanas han recuperado las historias de sus ancestras con el fin de modificar las narrativas y dignificar las historias. Este es el caso de Volver a casa de Yaa Gyasi, quien es una escritora ghanesa que migró con su familia a Estados Unidos desde los dos años. Creció en Alabama y estudió en la Universidad de Stanford y en el Taller de Escritores de Iowa. Durante su juventud viajó a Castillo de la Costa del Cabo en Ghana, donde recuperó diversos aprendizajes sobre su pasado, los cuales plasmó en Volver a casa. Gyasi es catalogada como una escritora afropolítica, específicamente de la diáspora. Su primera novela, Volver a casa, publicada en 2016, es considerada una narrativa neoesclavista (Goyal, 2019). El tema central de la novela es la trata de esclavos trasatlántica y las consecuencias del proceso. Por esa razón, en el relato se incorporan temáticas como el racismo, la guerra de secesión estadounidense, las independencias de los países africanos, la diáspora, la lucha por los derechos civiles de las poblaciones afroamericanas, entre otros. Sin embargo, para fines de este análisis, enfatizaré el proceso de esclavitud y las consecuencias para las poblaciones africanas.

En Volver a casa, Gyasi realiza un recorrido histórico de larga duración. La temporalidad inicia aproximadamente en el siglo XVI y llega hasta nuestros días. Por su parte, los espacios geográficos en los que se desarrolla la novela son la costa oeste africana y el este de Estados Unidos. Gyasi representa las transformaciones en las dinámicas sociales de las poblaciones africanas a partir de la historia genealógica de dos hermanas: Effia, quien es obligada a casarse con un gobernador inglés, y Esi, quien es capturada y enviada a las plantaciones estadounidenses (Gyasi, 2016).

Cada uno de los capítulos es la historia de un personaje: los dos primeros comienzan con las hermanas en la costa africana y posteriormente se van narrando las historias de sus descendientes de manera alternada. Cada apartado se puede leer de manera autónoma, sin embargo, como menciona Gyasi, "la riqueza se encuentra al leerlo en conjunto" (Gyasi en Goyal, 2019, 478). En la novela, la voz narrativa es omnisciente y nos habla de las experiencias, vivencias y sentimientos de las y los protagonistas a partir de imágenes que nos sitúan en los diferentes espacios temporales.

Como ya se mencionó, el tema central de la novela es la esclavitud, que fue un proceso de deshumanización y apropiación de los cuerpos negros. Esta dinámica, no sólo implicó el traslado de hombres y mujeres del continente africano a otras regiones del mundo, sino que también engendró guerras y desestructuró las relaciones de poder existentes en el continente africano. Así, el proceso de esclavitud estableció las bases materiales para la instauración de la violencia estructural en el continente, ya que además de las guerras impuestas, la captura de mujeres y 
hombres jóvenes fue el eje que orientó al proceso, despojando al continente de sujetas y sujetos esenciales para el bienestar de las comunidades (Rodney, 1982). En Volver a casa, Gyasi no esencializa las acciones de las poblaciones africanas durante el proceso de esclavitud; de hecho, resalta la participación de algunos pueblos africanos en la dinámica esclavista. No obstante, también enfatiza que esta "colaboración" respondió a las relaciones asimétricas de poder entre los africanos y los europeos. En su narración, Gyasi menciona tanto la disputa entre los fante y los asante, como las consecuencias para ambas comunidades por el comercio de esclavos y esclavas encabezado por los británicos: "Ya fuese robando, mintiendo o prometiendo una alianza a los fante y poder a los asante, el hombre blanco siempre hallaba el modo de conseguir lo que quería".

Gyasi también resalta las diferencias entre los sentidos de mundo africanos y europeos. Por ejemplo, en el capítulo de Effia se menciona: "La necesidad de llamar a una cosa 'buena' y a otra 'mala', a esto 'blanco' y a aquello 'negro', era un impulso que Effia no comprendía. En su aldea, todo era todo. Todo se apoyaba en todo lo demás". Así, en la novela se resalta el hecho de que la esclavitud fue el ancla para instalar un sistema de dominación jerárquico y dicotómico, que se sustenta en la creación de una otredad, en la invisibilización de lo opuesto y en la universalización de lo europeo (Tamale, 2020).

Asimismo, en el relato se critican las formas de vida impuestas por el sistema imperante, como el individualismo y el egoísmo. Por ejemplo, Ma Ake, una de los personajes menciona: "-El dios del hombre blanco — continuó ella- es igual que el hombre blanco. Se cree que es el único dios, de la misma manera que el hombre blanco se cree que es el único hombre" (Gyasi, 2016, 139). Esta mención no sólo es una crítica a la colonización, sino a todo el sentido de mundo y valores que acompañó a la modernidad. Es una alegoría para cuestionar nuestra socialidad.

En Volver a casa Gyasi también resalta la violencia inherente a la esclavitud, a partir de la cual los cuerpos de las y los africanos se convirtieron en propiedad privada de los europeos, quienes podían hacer con ellas y ellos lo que quisieran, incluso matarles. Gyasi, describe los traslados de personas después de las guerras de captura mencionando que "los tratantes les golpeaban las piernas con palos para que se apresurasen. Llevaban casi la mitad de esa semana marchando día y noche, y a los que no podían seguir el ritmo les daban con los palos hasta que por arte de magia, podían caminar".

Al hablar de las violencias, Gyasi utiliza eufemismos. Así, las descripciones parecen sutiles en comparación con las historias que se han recuperado de ese periodo, lo cual demuestra que la estrategia de comunicación política no sólo pretende nombrar o recordar estas historias, sino también recuperarlas desde una perspectiva decolonial que no reproduzca las imágenes de violencia a las que nos ha acostumbrado la modernidad colonial-capitalista-patriarcal. Incluso, la crítica a la 
colonialidad" se puede observar cuando en la novela se menciona: "si recurrimos al hombre blanco para formarnos, solo aprenderemos lo que el hombre blanco quiere que aprendamos".

Durante ese periodo, las mujeres no sólo sufrían de violencia directa expresada en azotes, algunas de ellas fueron violentadas física y simbólicamente cuando fueron obligadas a parir en los traslados o cuando se les propinaban golpes que les producían abortos. Asimismo, las esclavas tenían que pasar largos periodos en condiciones insalubres en los castillos habitados por los oficiales coloniales antes de ser embarcadas, y durante esos periodos también sufrían violencias y humillaciones por parte de soldados y líderes europeos, quienes denigraban su ser incluso a partir de violaciones (Bush, 2008, 679-680). Gyasi recupera estas situaciones en el relato de Esi:

\begin{abstract}
Al cabo de poco tiempo se abrió la puerta de la mazmorra y por el hueco se coló un resquicio de luz. Entraron un par de soldados, pero les pasaba algo raro. Sus movimientos parecían desestructurados, carentes de orden. Esi ya había visto a hombres borrachos de vino de palma; las caras enrojecidas y los gestos exagerados. Movían las manos como si quisieran abarcar el aire que los rodeaba.

Los soldados echaron un vistazo a su alrededor y las mujeres se pusieron a cuchichear. Uno de ellos cogió a una de las que había al fondo y la empujó contra la pared. Sus manos se abrieron camino hasta sus pechos y le recorrieron el cuerpo de arriba abajo, cada vez más abajo, hasta que el sonido que se le escapó a la mujer de entre los labios fue un alarido $(2017,56)$.
\end{abstract}

En los análisis históricos se ha mencionado que las violaciones eran una práctica común entre los esclavistas. De hecho, se dice que antes de zarpar, una mujer joven era enviada a la cabina del capitán para que este la violara (Bush, 2008, 687). La concepción de los cuerpos africanos como propiedad europea proyectó a las mujeres como objetos sexuales al servicio exclusivo de los hombres blancos. No obstante, las violaciones no respondían a impulsos sexuales ni a actos aislados, ya que esta acción tenía como objetivo fundamental subordinar y disuadir cualquier tipo de resistencia organizada por las mujeres. Asimismo, un acto que puede brindar placer, fue transformado en una acción de tortura y humillación, lo que demuestra el grado de planeación y brutalidad de la profanación de los cuerpos femeninos (Robertson, 2015, 69).

Algunas mujeres que quedaron embarazadas tras las violaciones fueron obligadas a abortar. No obstante, otras tuvieron hijos que contribuyeron a la economía esclavista. Así, las mujeres africanas no sólo realizaron trabajo esclavo y doméstico no remunerado, sino que también fueron "cuerpos violables" para "satisfacer" los deseos masculinos y, al mismo tiempo, garantizar el "capital" humano del sistema. De tal suerte, las violencias contra las mujeres africanas no sólo estuvieron

\footnotetext{
2 De acuerdo con Tamale (2020), la colonialidad es un sistema ideológico instaurado con la colonización europea que incluye "la producción de conocimientos y el establecimiento de órdenes sociales" para garantizar la explotación y dominación de las ex metrópolis.
} 
atravesadas por el género, sino que hubo una interseccionalidad de este eje de dominación con el de raza (Crenshaw, 1991, 1242).

Bajo la lógica de acumulación capitalista hay una dualidad en la naturaleza del trabajo de las mujeres africanas, ya que a pesar de que, en teoría, el espacio de las mujeres era exclusivamente el privado, las mujeres negras también participaban en el espacio público cuando era necesario para la reproducción del capital. Lo anterior también demuestra que "ser mujer es una construcción social que se da en un tiempo y un espacio determinados" (Peredo, 2003, 56) y no sólo una condición establecida por la bio-lógica ${ }^{3}$.

\begin{abstract}
El doble estatus de esclava - esclava y mujer - le otorgaba a su amo un cierto grado de flexibilidad para formular sus asignaciones laborales. Cuando necesitaba una mano para trabajar el campo, su condición como cuerpo esclavo tenía prioridad sobre las consideraciones de género, y era obligada a trabajar duro junto con los hombres. Al mismo tiempo, la creencia del amo de que la mayoría de las formas de servicio doméstico requerían la atención de una mujer, reforzó entre las esclavas el papel tradicional de la mujer como trabajadora del hogar (Jones, 1982, 249).
\end{abstract}

A pesar de las violencias referidas, en Volver a casa se resalta la fuerza y resistencia de las mujeres frente a las dinámicas de subordinación a las que fueron sometidas. Por ejemplo, Kojo, el nieto de Esi, fue entregado a Aku, una mujer esclava que lo sacó de los territorios del sur de Estados Unidos para que pudiera crecer como un hombre libre. Esto no hubiera sido posible sin la organización de su madre, Ness, y Akua, lo que demuestra las constantes resistencias de las mujeres en contra del sistema de subordinación impuesto.

Además, en la obra hay una crítica directa contra la colonialidad: "el único cambio sería que reemplazarían un tipo de ataduras por otras: grilletes que sujetaban manos y pies por ataduras invisibles que abarcaban la mente". Pero Gyasi no sólo reprueba la colonialidad, también invita a generar un orden social diferente. De hecho, todos los relatos están vinculados por una piedra que se transmite de generación en generación, la cual es una alegoría para volver a África y recuperar la dignidad de los pueblos, lo que enfatiza el carácter decolonial de la obra.

\title{
La flor púrpura, el cristianismo y la transición a la ética económico-capitalista
}

Con la formalización de la colonización, las violencias en contra de las mujeres se transformarían. De hecho, éstas ya no sólo serían ejercidas por los europeos, sino que también las practicarían los hombres africanos que fueron incorporados a la estructura de dominación (en una relación de inferioridad con respecto al hombre europeo). "Las nuevas costumbres inventadas, se derivaban exclusivamente de

\footnotetext{
3 Oyèwùmi menciona que la preeminencia de lo visual en la forma de clasificación y jerarquización occidental ha generado una bio-lógica que diferencia a los hombres de las mujeres a partir de una característica visual: los órganos genitales externos.
} 


\section{Adriana Franco Silva}

informantes masculinos, por lo que las 'creencias de las mujeres indígenas' seguían sin conocerse" (Ranger, 1982). Esta situación perduraría tras las independencias, porque quienes ocuparon los puestos de control estatal fueron los hombres.

La flor púrpura, primera novela de Chimamanda Ngozi Adichie, publicada en 2003, refleja algunas de las violencias que vivieron las mujeres durante ese periodo. Adichie es una escritora nigeriana que creció en un campus universitario debido a los trabajos de su madre y padre. Migró con su familia a Estados Unidos cuando tenía 19 años y estudió en Filadelfia. Ahí, como Gyasi, comenzó a adentrarse en el pasado histórico de su país. Actualmente vive largos periodos tanto en Estados Unidos como en Nigeria (Adichie en Salazar, 2017).

La personaje principal de la novela de Adichie es Kambili, quien a su vez funge como la narradora del relato. Kambili es una adolescente nigeriana que goza de privilegios económicos debido a que su padre es un gran empresario. Sin embargo, dentro de su hogar está subsumida a una profunda relación de violencia con su progenitor. A partir de las imágenes de sus experiencias y emociones, Kambili nos va situando en el contexto de la novela y nos va compartiendo su arraigada educación cristiana. Las descripciones de la narración son tan detalladas que incluso nos permite distinguir olores, sabores y nos hacen sentir la tristeza, confusión e incomodidad de la protagonista.

La flor púrpura se desarrolla en Nigeria, principalmente en Enugu, que es donde vive Kambili, y en Nsukka, donde vive su tía Ifeoma. El periodo temporal que abarca la novela es corto, ya que incluye los relatos de Kambili por alrededor de cuatro meses. La flor púrpura se ubica en el periodo poscolonial y se divide en cuatro capítulos: los títulos de los tres primeros hacen referencia directa al cristianismo, mientras que el último sugiere la liberación de Kambili. La forma e implicaciones de la imposición del cristianismo con la colonización es el tema central de la novela, y a partir de este se articulan otros como la violencia de género, la represión gubernamental, la migración, el racismo, el clasismo, entre otros.

A pesar de que la violencia descrita en la novela nace de la ortodoxia cristiana, Adichie no reproduce la dicotomía jerárquica colonial. Es decir, aunque hace una fuerte crítica al cristianismo, considera que el problema ha sido la forma en la que éste se impuso en su país. Esto se puede observar con el desarrollo del personaje del padre Amadi, quien es un sacerdote cristiano que difunde la palabra de su dios por medio del vínculo, interacción y diálogo con las comunidades.

A través de La flor púrpura, Adichie también contrasta lo precolonial —reflejado en el personaje de papa-Nnukwu y abuelo de Kambili- con el proyecto modernocolonial-capitalista-patriarcal - representado por Eugene, padre de Kambili. En la novela hay varios elementos que son importantes para el análisis de las transformaciones de las dinámicas comunitarias a partir de la colonización. En primer lugar, los vínculos con el poder, ya que, si bien este se centraba en las relaciones humanas durante el periodo precolonial, con la colonización europea el prestigio social estaría asociado directamente con las riquezas materiales que se poseían, como lo demuestra el estatus social de Eugene. 
En segundo lugar, la dualidad "irreconciliable" entre lo tradicional y lo moderno. Así, el poder se sustentó en términos dicotómicos centrados en un desarrollo vinculado a la modernidad. Tras las independencias, quienes se establecieron en los centros de poder fueron las poblaciones que tuvieron acceso a la educación occidental, las cuales, en su mayoría, rechazaron las tradiciones africanas y abrazaron las europeas, reproduciendo el discurso moderno colonial (Fanon, 2009). Esta situación se puede observar en La flor púrpura cuando Eugene se niega a visitar a su padre o permitir que sus hijos interactúen con él, debido a que papa-Nnukwu no se convirtió al cristianismo y, por lo tanto, consideraba que era un pagano alejado de la modernidad.

En tercer lugar, la colonización impuso un sistema sexo-diferenciado con jerarquías de género que omitieron, y en algunos casos destruyeron, las instituciones que permitían que las mujeres tuvieran autonomía en las relaciones comunitarias (van Allen, 1972, 165). A diferencia de las jerarquías de género occidentales, para las poblaciones yorùbá e igbo precoloniales, la organización social se basaba en la senioridad y en los vínculos comunitarios, no en el sexo de las personas. Así, "la senioridad, es relacional y dinámica y a diferencia del género, no se enfoca en el cuerpo" (Oyèwùmi, 2017, 56). Asimismo, los términos de parentesco y las categorías políticas no tenían una especificidad de género y en muchos casos dependían de las relaciones familiares y comunitarias. Esta condición es recuperada por Adichie en su novela cuando Kambili menciona:

La primera vez que oí a tía Ifeoma llamar así a madre años atrás, me horrorizó el hecho de que una mujer se dirigiera a otra llamándola "mi esposa". Cuando le pregunté a padre, me explicó que era una costumbre de la tradición pagana, que correspondía a la idea de que era la familia entera y no solo el hombre quien tomaba a la mujer por esposa (Ngozi, 2003, p. 68).

Finalmente, la normalización de la violencia es otro de los cambios que fue recuperado por Adichie. Por ejemplo, en la narración hay una fuerte violencia simbólica interiorizada en Kambili a través de los discursos religiosos. Así, Kambili muestra un profundo autocontrol para hacer lo que su padre quiere y no lo que ella desea. Asimismo, esta violencia también se refleja en sus inseguridades, temores e, incluso, en su incapacidad para sonreír. La violencia directa también está presente en el texto. De hecho, la violencia doméstica que Eugene ejerce es tan profunda que todos los integrantes de la familia tienen que visitar en al menos una ocasión el hospital.

Esta violencia se sustenta en los preceptos de un cristianismo ortodoxo que se niega a la desobediencia de los "súbditos" de la familia frente a los mandatos del padre de la casa. Incluso, esta violencia revictimiza y culpa a quienes la sufren, profundizando la violencia simbólica. Por ejemplo, en una ocasión, los golpes de Eugene provocan que Beatrice, la madre de Kambili, abortara. Empero, ésta es responsabilizada por lo sucedido. Kambili relata: “Más tarde, durante la cena, padre anunció que íbamos 
a recitar dieciséis novenas para el perdón de madre 4 . Y el domingo después de Adviento nos quedamos al finalizar la misa e iniciamos las novenas".

En la narración podemos constatar que la violencia de género se normaliza en Enugu, que es el espacio que se vincula con la modernidad. Sin embargo, en Nsukka, el espacio de diálogo e interacción entre lo moderno y lo tradicional, esta violencia es cuestionada. De hecho, tía Ifeoma plantea alternativas para que ésta deje de ocurrir. A pesar de esto, Nsukka no se libra de la violencia estructural contra las mujeres, lo cual se ve reflejado en la dificultad de tía Ifeoma, siendo madre viuda, para ganar recursos económicos con los cuales alimentar a sus tres hijos.

En la novela se hace énfasis en que Eugene eran un hombre generoso hacia el exterior, aunque las personas a las que asistía tenían que reproducir los preceptos cristianos y modernos. Sin embargo, en su casa el orden se mantenía por la violencia y la represión. Considero que el objetivo de Adichie con estas descripciones, no era solo enfatizar la violencia doméstica instaurada por la colonización, sino también hacer una metáfora que cuestionara las relaciones de poder mundial. Es decir, la representación de Eugene se puede extrapolar a Nigeria y a otros países del sur global cuyos gobiernos están dispuestos a entregar sus riquezas naturales, teniendo una buena relación al exterior, mientras mantienen regímenes militares y represivos al interior.

Al igual que en el caso de Volver a casa, en La flor púrpura no solo se habla de la violencia doméstica que vive Kambili y su familia, también se resalta la autonomía de su tía y la felicidad, inteligencia y fortaleza de su prima Amaka, una mujer que cuestiona las estructuras de dominación del sistema y busca alternativas de vida, donde las diferentes cosmovisiones puedan coexistir.

La experiencia de Kambili al vivir con su tía y los discursos de su prima hacen que ésta se cuestione su realidad y la violencia ejercida por su padre, por lo que a pesar de que la novela expone un caso complicado, no sólo muestra a Kambili como una víctima del proyecto moderno-colonial-capitalista-patriarcal, sino que proporciona reflexiones para la emancipación. Incluso, el símbolo de la flor púrpura es una alegoría para rechazar la violencia y diseñar utopías:

El desafío de Jaja [hermano de Kambili] me parecía ahora igual que el experimento con los hibiscos púrpuras de tía Ifeoma: raro, con un trasfondo fragante de libertad, pero de una libertad distinta a la que la multitud había clamado, agitando hojas verdes en Government Square, tras el golpe. Libertad para ser, para hacer.

\section{Florescencia y la profundización de la violencia con el ajuste estructural}

Como ya se ha mencionado, tanto en los sistemas de conocimiento como en las expresiones artísticas occidentales se han omitido las historias e instituciones de las mujeres africanas. Sin embargo, también se han ocultado temas que conciernen y

\footnotetext{
${ }^{4}$ Las cursivas son para enfatizar lo mencionado.
} 
atraviesan nuestra cotidianeidad. Florescencia de Kopano Matlwa (2018), rompe con esta normalización tan fuertemente arraigada en la literatura.

Matlwa nació en Pretoria, Sudáfrica, en 1985, por lo que a la caída del apartheid tenía apenas nueve años. Estudió en Oxford y actualmente reside en Johannesburgo. Matlwa estudió medicina y también es novelista. Se considera a sí misma como parte de una generación que busca un sueño común: "ver la dignidad devuelta a nuestro continente en nuestra propia vida" (Matlwa, 2016).

Florescencia, su tercera novela, es contada por Masechaba, alter ego de Kopano Matlwa y voz narrativa del relato. La narración está situada en Sudáfrica en el periodo post apartheid y durante el reforzamiento del proyecto capitalista neoliberal. De tal suerte, el eje central de Florescencia son los retos a los que se enfrenta Sudáfrica después del apartheid, por lo que incorpora temas como las relaciones desiguales de poder mundial, la violencia y la xenofobia.

Florescencia nos hace pensar que estamos leyendo el diario de Masechaba, por lo que es muy fácil empatizar con la personaje e incluso experimentar sus emociones, ya que la conocemos desde la intimidad. La novela está dividida en cuatro partes y en toda la narración es posible identificar el vínculo religioso de Matlwa. El primer capítulo habla sobre la menstruación, el segundo comienza incorporando el debate de la xenofobia, el tercero describe la violencia sexual contra las mujeres y el cuarto hace una alegoría a la transformación de la dinámica social.

El texto incorpora temas que no son comunes en las obras literarias, porque a diferencia de la mayoría de estos relatos, Florescencia no está escrita por, sobre y para hombres. Así, por ejemplo, Kopano Matlwa describe los dolores que la menstruación le provocan a Masechaba y los estigmas occidentales desarrollados en torno a ese proceso fisiológico.

\begin{abstract}
Enrollaba puñados de papel higiénico en mis bragas de Woolworth; me rozaba y era incómodo, pero no podía compararse con la incomodidad que sentiría al confesarle a mamá que había pecado y que sangraba como castigo.[...]

Después aprendería en catequesis que esos cántaros de suero que manaban periódicamente de mi vagina no eran un castigo divino, sino una parte sana y fisiológicamente necesaria de la vida de las mujeres que no solo debíamos aceptar, sino también celebrar (Matlwa, 2018, p. 10).
\end{abstract}

Sin embargo, para Masechaba, los dolores menstruales eran insoportables, por lo que constantemente se pregunta por qué debía ensalzar el hecho de poder "traer vida al mundo", cuestionando los roles de género vinculados con la maternidad. El contexto en el que se desarrolla la obra es el periodo neoliberal, cuando la profundización de la extracción de los recursos geoestratégicos, los recortes a programas sociales y el adelgazamiento general del Estado se convirtieron en elementos de agudización de las violencias en el sur global.

En ese sentido, dos de los temas recuperados por Matlwa son la xenofobia, que se sustenta en la modernidad dicotómica de exclusión, y las violaciones, basadas en las relaciones de subordinación de lo femenino. La xenofobia en Sudáfrica se dirige 
particularmente contra personas negras migrantes que se trasladan a Sudáfrica en busca de mejores oportunidades de vida. Sin embargo, estos migrantes han sido estigmatizados y asociados con la criminalidad. Asimismo, se argumenta que estas personas quitan trabajos a los sudafricanos y que son una amenaza para el país, a pesar de que no hay ejemplos o datos para sustentar dichas afirmaciones (Salomon y Kosaka, 2013, 8).

Estas representaciones no son creaciones autónomas de las poblaciones sudafricanas, más bien tienen que ser entendidas como parte de la violencia simbólica que sustenta las estructuras del sistema capitalista a nivel mundial. Es decir, la xenofobia ha sido la violencia que se apoya en los discursos que subordinan a ciertas poblaciones, para mantener el statu quo desigual, frente a un contexto de crisis y de reducción de las capacidades estatales. De tal suerte, la inconformidad contra la incapacidad de los gobiernos para garantizar niveles de vidas dignos a sus ciudadanas/os, es extrapolado a quienes han sido representadas como las otras y otros bajo la lógica estatal.

En el relato de Matlwa, Masechaba, quien estudió medicina, conoce y se hace amiga de Nyasha, una cirujana zimbabuense que le ayuda a cuestionar la realidad sudafricana. Cuando Masechaba presenta a Nyasha menciona: "En el hospital todos sabían que, de no ser por su nacionalidad extranjera, ya habría obtenido el título de obstetra-ginecóloga, pues era una cirujana excelente".

Matlwa también resalta la violencia sexual contra las mujeres ${ }^{5}$, particularmente contra aquellas que se oponen a lo establecido por las jerarquías de género occidentales. Esto no es un problema exclusivo de las poblaciones sudafricanas o incluso africanas, sino que atraviesa a la mayoría de las mujeres en las diferentes regiones del mundo. De hecho, la violencia contra las mujeres se profundizó durante el periodo neoliberal y, por lo tanto, con la imposición de los programas de ajuste estructural por parte de los organismos financieros internacionales.

La 'globalización' es un proceso de recolonización política que intenta otorgar al capital un control incuestionable de las riquezas naturales del mundo y del trabajo humano, y esto no se puede lograr sin atacar a las mujeres, quienes son directamente responsables de la reproducción de sus comunidades. No es sorprendente que la violencia contra las mujeres ha sido más intensa en aquellas partes del mundo (África sub-sahariana, América Látina, Sureste

\footnotetext{
${ }^{5}$ A comienzos del siglo XXI, algunos estudios mostraban cifras alarmantes de la violencia sexual contra las mujeres en Sudáfrica (Moffett, 2006, 129). Sin embargo, es importante señalar que tener estadísticas precisas de la violencia de género es complicado, tanto por los costos de la producción metodológica y recaudación de datos, como por los posibles sesgos en el análisis (Mashishi, 2020). En países que han sido racializados es aún más complejo, debido a que las cifras tienden a sobrerrepresentarse por la colonialidad del saber. Así, el discurso que vincula la violencia sexual con espacios pobres o racializados es simplemente una justificación que disfraza la violencia estructural inherente al sistema.

A pesar de esto, es importante reconocer que la violencia sexual es un problema al que se enfrenta Sudáfrica y que, más allá de las cifras, es relevante considerar que estas violencias son un problema estructural que reducen las potencialidades de las mujeres, por lo que hacer justicia cognitiva implica reconocer estas realidades, sin reproducir discursos coloniales, para que se puedan diseñar alternativas.
} 
Asiático) que son ricas en recursos naturales y están marcadas por las empresas comerciales, y donde las luchas anticoloniales han sido más fuertes. Maltratar a las mujeres es funcional para los 'nuevos centros económicos'. Esto facilita el camino para el acaparamiento de tierras, privatizaciones y guerras que por años han devastado regiones enteras (Federici, 2018, 42).

Sudáfrica es uno de los países líderes en producción minera de riquezas que son estratégicas para la reproducción del sistema moderno-colonial-capitalistapatriarcal, para el reposicionamiento de la tecnología y, por lo tanto, para el mantenimiento de la hegemonía (Ceceña y Porras, 1995). Sólo por mencionar un ejemplo, de acuerdo con el U.S. Geological Survey, en 2015 Sudáfrica representaba el $74 \%$ del platino extraído a nivel mundial y 59\% del rodio refinado. El primero es fundamental para casi todas las industrias capitalistas, mientras que el segundo es utilizado para el refinación del petróleo, por lo cual, ambos son geoestratégicos. Así, mientras los intereses de las grandes corporaciones a nivel internacional se mantienen, las violencias en los nodos extractivos se profundiza.

Sin embargo, la extracción de riquezas naturales no es el único saqueo al que se enfrenta Sudáfrica, y esto es recuperado por Matlwa cuando Nyasha señala: "para ellos, nuestro pueblo es un instrumento para perfeccionar sus conocimientos médicos, que luego aplicarán a los pacientes blancos en el sector privado". Con esto se resalta la apropiación y explotación de las mentes africanas para beneficiar a los centros de poder en detrimento de los países africanos.

En su relato, Matlwa también cuestiona la normalización de la violación con fines "correctivos". El concepto de las violaciones "correctivas" ha sido utilizado para excusar las violaciones ejercidas contra las mujeres lesbianas, pero también contra las que se oponen a las políticas y prácticas que sustentan el ordenamiento colonialcapitalista-patriarcal. En Florescencia, Masechaba fue violada y este acto fue justificado porque ella estaba participando en la organización de una marcha anti xenófoba. Cuando describe el acto, Masacheba menciona que los hombres le decían: "Te gustan los kwere-kwere pipi, ¿eh? Eso es porque nunca lo has probado con un sudafricano de verdad. Hoy te convertiremos en una verdadera mujer sudafricana" (Matlwa, 2018, 70).

Como ya se mencionó, las violaciones no son actos espontáneos, tienen una planeación y una intencionalidad que se sustenta, principalmente, en demostrar "la posición" de las mujeres en este sistema. Así, cuando una mujer no actúa como lo determinan las normas sociales capitalistas, entonces se piensa que debe ser sancionada por los hombres (Moffett, 2006, 133-139).

De tal suerte, las denominadas violaciones "correctivas" son formas de ejercer dominio sobre los cuerpos de las mujeres que se "atreven" a cuestionar al sistema de dominación. Matlwa no sólo recupera la violencia directa que enfrentan las mujeres sudafricanas, también resalta la simbólica. Por ejemplo, cuando Masechaba se enfrenta a los discursos que la revictimizan tras la violación, ella piensa:

La enfermera Agnes me había advertido: 
-Doctora, ¿por qué se trae esa ropa tan bonita al trabajo? No nos vestimos así para las guardias nocturnas.

La enfermera Palesa me había advertido:

-Doctora, a la comunidad no le gusta ese asunto de la petición. Se está involucrando demasiado.

[...] Tendría que haber escuchado. Tendría que haber estado más tranquila, más callada, más serena, más centrada. Me entusiasmé demasiado. Y por eso me violaron aquellos hombres (Matlwa, 2018, 73).

Asimismo, Matlwa cuestiona la pasividad frente a las opresiones e incita a la acción utilizando la figura literaria del conflicto, sobre todo cuando su personaje principal cuestiona su praxis frente a la xenofobia: "soy una cobarde. Si esto fuese el apartheid, yo sería uno de esos blancos que se limitó a guardar silencio mientras veía lo que ocurría". A diferencia de Gyasi, Matlwa es explícita en la descripción de la violencia, lo que desde mi perspectiva pretende interpelar a las y los lectores para que se posicionen y actúen frente a la violencia.

Tras la violación, Masechaba se dio cuenta de que estaba embarazada en un momento en el que ya no podía abortar. A pesar de esto, Matlwa utiliza la antítesis para construir una alternativa. Así, Masechaba se cuestiona si debería decirle a su hija que cuando se enteró del embarazo había querido morir, pero que su vida la había impulsado a vivir. Asimismo, Mpho, su hija, también representa una alegoría para la lucha y el cambio social.

Actualmente, las mujeres en Sudáfrica se siguen organizando y siguen activas para hacerle frente a la violencia sexual en su país. La mayoría participa y se estructura en las universidades, otras más lo hacen a partir de las organizaciones de la sociedad civil. Empero, sin importar desde dónde lo hacen, lo relevante es que no se han quedado calladas ni han tolerado las violencias contra sus cuerpos, mentes y sentires (Mitchell, et. al., 2018, 321). Sus resistencias y movimientos tampoco han sido exclusivos de Sudáfrica, a lo largo y ancho del continente las mujeres se están organizando no solo para contener las violencias machistas, sino también para transformar las lógicas de producción, reproducción y consumo de este sistema de acumulación.

\section{Reflexiones finales}

Las resistencias y formas de organización de las mujeres africanas son múltiples y la literatura es sólo uno de los espacios que contribuyen a la lucha colectiva. Estas narraciones han sido una forma de visibilizar las historias omitidas, de analizar prácticas y saberes no dominantes, de rescatar las experiencias de las mujeres. En el caso de las novelas seleccionadas: Volver a casa de Yaa Gyasi, La flor púrpura de Chimamanda Ngozi Adichie y Florescencia de Kopano Matlwa, se plantean las violencias que viven o han vivido las mujeres africanas desde el establecimiento de la modernidad colonial-capitalista-patriarcal, pero también se vislumbran alternativas. 
En todas las novelas podemos encontrar las tres dimensiones de las violencias contra las mujeres. En el texto de Gyasi se describe la violencia directa en los azotes y violaciones contra las mujeres africanas capturadas durante el proceso de esclavitud. La estructural se refleja en la instauración de desigualdades con la inserción del continente al proyecto moderno-colonial-capitalista-patriarcal bajo una lógica de subordinación que marginaba de manera más profunda a las mujeres. Por su parte, la simbólica se expresa en los estereotipos, humillaciones y denigraciones a los que se enfrentaron las mujeres africanas durante ese periodo y con la intersección de las diferentes categorías de dominación.

En la novela de Adichie, la violencia directa está representada por los golpes que Eugene dirigía contra su familia. La estructural se analiza en la pobreza en la que vivían las mujeres sin marido o que mantenían vínculos con "lo tradicional", como lo demuestra el caso de tía Ifeoma. Por su parte, la simbólica se refleja en los discursos de terror impuestos por Eugene -interiorizados en la mente de Kambili-, los cuales no le permitían hacer y disfrutar de lo que ella quería. Asimismo, esta violencia también se plasma en la revictimización de los personajes violentados bajo el discurso de la ortodoxia cristiana, como sucedía constantemente con Beatriz.

Finalmente, en el relato de Matlwa, la violencia directa se observa en las violaciones "correctivas". La estructural se analiza a partir de las relaciones desiguales entre las poblaciones sudafricanas y las extranjeras, sustentadas bajo la lógica dicotómica nacional impuesta por la modernidad y fortalecida por la implementación del ajuste estructural, como lo muestra el caso de Nyasha. Por su parte, la simbólica se representa en los discursos de odio contra las mujeres y en la revictimización que sufre Masechaba tras la violación, la cual se proyecta como un castigo para que otras mujeres no se opongan a las reglas establecidas por el sistema patriarcal.

Las novelas utilizan diferentes figuras literarias como la metáfora, la antítesis, el recuerdo, entre otros. Por ejemplo, las imágenes son incluidas en los tres relatos para crear representaciones mentales que permitan que las lectoras se sumerjan y experimenten lo narrado. Tanto Gyasi como Adichie utilizan eufemismos para no reproducir discursos dicotómicos coloniales al describir actos de violencia, seguramente con la intención de comunicar desde otros puntos de enunciación. Por su parte, Matlwa relata las violencias de manera más descarnada con el objetivo de increpar a quien lee, probablemente porque la violencia que relata podría considerarse más cercana e incluso actual. Asimismo, las tres autoras usan alegorías para enfatizar que las cosas pueden cambiar, que las mujeres no tienen por qué seguir viviendo esas opresiones.

La literatura es un elemento importante para la construcción de subjetividades y cosmovisiones. Por esa razón, el hecho de que Gyasi, Adichie, Matlwa y muchas otras más estén incorporando temas de los cuales antes no se hablaba - porque eran considerados asuntos de mujeres - es fundamental para contribuir a la visibilización de las desigualdades e injusticias impuestas por este sistema. Asimismo, a partir de estos relatos, las mujeres africanas y las de otras regiones del 


\section{Adriana Franco Silva}

mundo podemos cuestionar nuestra cotidianidad, reflexionar las maneras en las que nos relacionamos con las y los demás, e imaginar y plantear formas de vida e interacción en las que la acumulación y la violencia no sean los ejes básicos de la producción y reproducción social.

Como ya se mencionó, la literatura no es la única forma de resistencia y organización para las mujeres. Sin embargo, es un espacio fundamental para generar otras representaciones y socialidades. Desde mi perspectiva, las tres novelas no sólo pretenden representar o recuperar historias pasadas, también buscan hacer una crítica al sistema de dominación y dar esperanza para construir alternativas. Matlwa se considera parte de la generación del punto de retorno, la cual desea recuperar la dignidad de las y los africanos cuestionando de dónde vienen y hacia dónde van. Tras el análisis de las novelas, me parece que Gyasi, Adichie y Matlwa están comprometidas con esa utopía decolonial, ya que con sus narraciones pretenden visibilizar las estructuras de poder que sostienen las relaciones de dominación y explotación para producir representaciones, conocimientos y órdenes sociales diferentes a los establecidos.

\section{Bibliografía}

Alvazzi del Frate, A. (2011). Average femicide rates per 100,000 female population in 25 countries and territories with high and very high rates, 2004-09. Small Arms Survey, Ginebra. Recuperado en: http://www.smallarmssurvey.org/fileadmin/img/highlights/Femicide-RN14fig2.pdf

Amadiume, I. (2017). La nueva pobreza de las mujeres. En Ellas [también] cuentan. Antología inédita de narrativa breve y poesía de escritoras africanas de expresión inglesa. Tenerife: Baile del sol.

Bush, B. (2008). 'Daughters of injur'd Africk': African women and the transatlantic slave trade. Women's History Review (15).

Cabanillas, N. (2020). Mujeres en África. En Diplomado en Estudios sobre África, PUEAA, Ciudad de México.

Ceceña, A. E. \& Porras, P. (1995). Los metales como elemento de superioridad estratégica. En A. E. Ceceña \& A. Barreda (coords.); Producción estratégica y hegemonía mundial. Ciudad de México: Siglo XXI.

Cejas Minuet, M. (2000). Pensar el desarrollo como violencia: algunos casos en África. En S. Devalle; Poder y cultura de la violencia. Ciudad de México: El Colegio de México. 
Comaroff, J. \& Comaroff, J. (2010). Africa Observed Discourses of the Imperial Imagination. En Grinker, et. al. (cords.) Perspectives on Africa A Reader in Culture, History and representation. Singapur: Wileu-Blackwell.

Crenshaw, K. (1991). Mapping the Margins: Intersectionality, Identity politics, and Violence against Women of Color. Stanford Law Review (43).

Fanon, F. (2009). Piel negra, máscaras blancas. Madrid: Akal.

Federici, S. (2018) Witches, Witch-Hunting and Women. Oakland: PM Press.

Fernández de la Reguera, A. (2017). Las bases culturales de la violencia de género y los procesos de autonomía de las mujeres. En J. Camargo y D. E. García (eds.) Matrices de paz. Ciudad de México: Bonilla Artigas Editores y Tecnológico de Monterrey.

González, F. (2017). Geografía y violencia. Una aproximación conceptual al fundamento espacial de la violencia. Ciudad de México: Monosílabo.

Goyal, Y. (2019). An Interview with Yaa Gyasi. Contemporary Literature, 60(4).

Gyasi, Y. (2016). Volver a casa. Barcelona: Salamandra.

Jones, J. (1982). "My Mother was Much of a Woman”: Black Women, Work, and the Family under Slavery. Feminist Studies (8).

Kakozi, J. B. (2020). Filosofía Ubuntu. En Diplomado en Estudios sobre África, PUEAA, Ciudad de México.

Martin, M. (2016). “More Power to your Great Self”: Nigerian Women's Activism and the Pan-African Transnationalist Construction of Black Feminism. Phylon (53), 2.

Mashishi, N. (2020). Are 40\% of South African women raped in their lifetime and only $8.6 \%$ of perpetrator jaled? En Africa Check. Recuperado de: https://africacheck.org/fact-checks/reports/are-40-south-african-women-rapedtheir-lifetime-and-only-86-perpetrators-jailed

Matlwa, K. (2016). What to do when a moonshot falls short. Ted Talk. Johannesburgo. https://www.youtube.com/watch?v=rACJHUid7Lk

Matlwa, K. (2018). Florescencia. Barcelona: Alpha Decay.

Mies, M. (2018). Patriarcado y acumulación a escala mundial. Madrid: Traficantes de sueños. 
Mitchell, C., et. al. (2018). Addressing Sexual Violence in South Africa: 'gender Activism in the making'. En Oinas, E., et.al. What Politics? Youth and Political Engagement in Africa. Leiden: Brill.

Moffett, H. (2006). "These Women, They Force Us to Rape Them": Rape as Narrative of Social Control in Post-Apartheid South Africa. Journal of Southern African Studies $32,(1)$.

Naciones Unidas (1994). Resolución 48/104. Declaración sobre la eliminación de la violencia contra la mujer. https://documents-ddsny.un.org/doc/UNDOC/GEN/N94/095/08/PDF/N9409508.pdf?OpenElement

Ngozi Adichie, C. (2003). La flor purpura. Barcelona: Random House.

Nzegwu, N. (1994). Gender Equality in a Dual-Sex System: The Case of Onitsha. Canadian Journal of Law and Jurisprudence, 7(1).

Ogbomo, O. W y Ogbomo, Q. O. (1993). Women and Society in Pre-Colonial Iyede. Anthropos (88).

Oyèrónké, O. (2017). La invención de las mujeres. Una perspectiva africana sobre los discursos occidentales del género. Bogotá: Editorial en la frontera.

Peredo Beltrán, E. (2003). Mujeres, trabajo doméstico y relaciones de género: reflexiones a propósito de la lucha de las trabajadoras bolivianas. En Mujeres y trabajo: cambios impostergables. Porto Alegre: Veraz Comunicação.

Ranger, T. (1983). El invento de la tradición en el África colonial. En E. Hobsbawm, \& T. Ranger; La invención de la tradición Barcelona: Editorial Crítica.

Robertson, C. (2015). We Must Overcome: Genealogy and evolution of Female Slavery in West Africa. Journal of West African History (1).

Salazar, C. (2017). Chimamanda Ngozi Adichie: "Nuestra época obliga a tomar partido". El País. Recuperado de: https://elpais.com/elpais/2017/10/01/eps/1506809126 150680.html

Schwab, G. (1984). Genesis of the subject, Imaginary Functions, and Poetic Language. New Literary History (15), 3.

Segato, L. (2016). La Guerra contra las mujeres. Madrid: Traficantes de sueños.

Solomon, H.y Kosaka, H. (2013). Xenophobia in South Africa: Reflections, Narratives and Recommendations. Southern African peace and Security Studies. (2), 2.

Tamale, S.(2020). Decolonization and Afro-Feminism. Ottawa: Daraja Press. 
Violencias contra las mujeres: análisis de tres novelas africanas recientes

USGS (2015) The Mineral Industry of South Africa. 2015 Minerals Yearbook Survey. Recuperado de: https://prd-wret.s3-us-west2.amazonaws.com/assets/palladium/production/atoms/files/myb3-2015-sf.pdf

Van Allen, J. (1972). "Sitting on a Man": Colonialism and the Lost Political Institutions of Igbo Women. Canadian Journal of African Studies (6).

Recibido: $10 / 12 / 2020$

Evaluado: $14 / 03 / 2021$

Versión Final: 04/03/2021 